\title{
Presente de branco: a perspectiva indígena dos brindes da civilização (Amazônia, século XIX)
}

White people's gift: the indigenous perspective of the gifts from civilization (Amazon, nineteenth century)

Márcio Couto Henrique ${ }^{\star 1}$

\section{RESUMo}

$\mathrm{O}$ artigo discute a maneira como os índios interpretavam os presentes ou brindes que lhes eram oferecidos como parte do processo de catequese e civilização na Amazônia do século XIX. A análise de documentos oficiais, relatos de viajantes e notícias de jornais permite constatar que os índios, muito longe de serem pessoas ingênuas que se deixavam seduzir por objetos de pouco valor, atribuíam significados próprios aos brindes, traduzindo-os e assimilando-os de acordo com regras determinadas por suas próprias culturas. A leitura indígena dos brindes demonstra que tais objetos não devem ser pensados apenas em torno de seu valor comercial, mas sobretudo pela dimensão simbólica que regulava essas transações do ponto de vista dos indígenas.

Palavras-chave: perspectiva indígena; brindes; Amazônia.

\section{Abstract}

The article discusses how the Indians interpreted the gifts offered to them as part of the process of catechesis and civilization in the nineteenth century Amazon. Starting from the analysis of official documents, travelers' accounts and newspaper reports it appears that the Indians, far from being naive people who let themselves be seduced by undervalued objects, ascribed their own meanings to the gifts, translating and assimilating them accordingly to the rules determined by their own cultures. The indigenous reading of the gifts shows that such objects should not be approached only by their commercial value, but mainly from the symbolic dimension which governed these transactions from the point of view of the natives.

Keywords: indigenous perspective; gifts; Amazon.

* Faculdade de História, Universidade Federal do Pará (UFPA). Belém, PA, Brasil. marciocouto@ufpa.br 


\section{“Mimos” PARA OS ÍNDIOS}

Em 1847, duas autoridades da província do Pará se reuniram para jantar numa aldeia de índios Munduruku chamada Curí, às margens do rio Tapajós, na Amazônia. De um lado, o bispo d. José Afonso de Morais Torres (18051865), em visita pastoral pelas paróquias e freguesias de seu bispado. Do outro, o tuxaua, ou cacique da aldeia, convidado pelo religioso para o jantar. Como nos dias anteriores, diante do bispo que não abria mão de usar a batina, o tuxaua procurou ostentar sua distinção e apareceu vestido com a farda que o distinguia dos demais índios a ele subordinados. ${ }^{3}$

Diante da mesa posta, entretanto, a situação se modificou a favor do bispo: o tuxaua não conseguiu manter a mesma distinção diante do religioso, pois "viu-se em aperto sem saber manejar o garfo e a faca". Constrangido pelo mau desempenho com garfo e faca às mãos, o índio Munduruku procurou não desperdiçar os outros recursos performáticos que lhe restaram naquela noite em que jantava com a maior autoridade religiosa da província. Dessa forma, dedicou-se com tal empenho à bebida que acompanhava o jantar que a garrafa de vinho "sofreu um ataque que eu não esperava", lamentou-se, desgostoso, o bispo. Em seguida, ao receber de presente do bispo um rosário, o tuxaua, "blasonando-se de bom cristão, disse que [o rosário] era pequeno e que queria um grande, porque não rezava pouco como criança". ${ }^{4}$

Esse episódio nos permite refletir sobre a apropriação que o tuxaua Munduruku fez dos objetos exteriores à cultura tradicional de seu grupo: fardamento, garfo e faca, vinho e rosário foram traduzidos pelo índio em seus próprios termos, revelando aproximação bastante peculiar desses ícones da civilização que o governo imperial procurava impor aos índios no Brasil do século XIX. Na Amazônia, a política indigenista imperial sofreu as consequências daquela que é considerada uma das maiores revoltas populares da história do Brasil: a Cabanagem (1835 e 1840), que causou a morte de mais de $30 \mathrm{mil}$ pessoas, com graves danos à economia da região. Findo o conflito, o desafio era reconstruir a província do Grão-Pará, reorganizar a agricultura e o comércio e manter o controle sobre os trabalhadores, de modo a evitar novas cabanagens (Ricci, 2006; Harris, 2010).

A atividade missionária no Brasil imperial passou a ser regulada pelo Decreto 426, de 24 de julho de 1845, também conhecido como Regulamento das Missões (Sposito, 2006; Sampaio, 2009). Conforme observou Maria Hilda Baqueiro Paraíso, a grande fonte de inspiração do Regulamento das Missões de 
1845 era o Diretório Pombalino, "pois como ele, o Regulamento estava voltado para promover a adequação sociocultural dos grupos indígenas, a partir da administração da vida cotidiana dos aldeamentos" (Paraíso, 1998, p.521). Estes deveriam se aproximar do modelo das povoações civilizadas, com igrejas, oficinas, cemitérios, cadeias públicas e livre comércio entre índios e brancos. $\mathrm{O}$ aldeamento era um local de transição, onde os índios deveriam aprender o hábito do trabalho regular voltado para a produção de excedentes, além de outros hábitos associados ao padrão de vida tido como civilizado (uso de roupas, língua portuguesa e crenças católicas, entre outros). Depois de "civilizados", deixavam de ser considerados índios, sendo definidos como "confundidos na massa da população", o que permitia liberar suas terras para a colonização.

O Regulamento das Missões recuperou experiências de outras propostas de civilização dos índios, o que incluía, além da catequese, a criação de escolas para crianças nas aldeias, o desenvolvimento dos ofícios e "artes mecânicas", o estimulo à produção de alimentos para autossustentação e comercialização do excedente, a atração e descimento dos índios considerados "errantes" e a prática da propriedade coletiva. Havia, também, a preocupação com as fronteiras nacionais, ameaçadas pelos países vizinhos (Sampaio, 2009).

Foi nesse contexto que ocorreu o jantar entre o tuxaua Munduruku e o bispo do Pará. De acordo com o Regulamento das missões, caberia ao Diretor Geral distribuir aos Diretores Parciais e missionários os objetos destinados aos índios pelo governo. Tais objetos são referidos na documentação do século XIX como brindes ou mimos e constituíam elemento fundamental na política de atração e manutenção dos indígenas nos aldeamentos.

Assim como o costume de distinguir as lideranças indígenas, a oferta de presentes aos índios constituía prática antiga e espalhada além das fronteiras brasileiras. Conforme observou Patrícia Sampaio, o sucesso do descimento dos índios estava baseado em permutas sistemáticas: "os presentes e as trocas eram o ponto de sustentação dos contatos. Para que os índios se deslocassem de seus locais de origem, o missionário acenava com objetos variados" (Sampaio, 2001, p.40). Outros autores se referem às longas negociações em que os missionários e seus intérpretes faziam ofertas de facas, tesouras, agulhas, tecidos e miçangas, entre outros produtos, procurando convencer os índios das comodidades da vida nas missões (Carvalho, 2012; Roller, 2014; Mandrini, 2014).

Definidos pelas autoridades da província como instrumentos de atração dos índios à civilização, em muitas situações é possível identificar como determinados povos indígenas faziam leitura desses brindes em seus próprios 
termos, apropriando-se dos presentes que lhes eram dados sem, no entanto, abandonar seus costumes tradicionais. É a leitura indígena dos brindes que este artigo pretende problematizar.

Sabiam os presidentes da província o quanto seria difícil convencer os índios a abrir mão da vida independente que tinham em troca da vida sedentária nos aldeamentos, com trabalho regular e diário, obedecendo a autoridades por eles desconhecidas (Henrique, 2013). Vejamos o que disse Jerônimo Francisco Coelho, presidente da província do Pará, a respeito dos brindes utilizados para atrair os índios:

A fim de atrair os índios é preciso, primeiramente, brindá-los com mimos e presentes, e, depois de aldeá-los, faz-se mister pagar a um missionário, que os assista, dar-lhes roupa, ferramentas e novos brindes; e para poder empregar todos estes meios em todas as missões projetadas ou principiadas, grandes somas se fazem precisas... ${ }^{5}$

Dessa forma, o projeto de catequese e civilização dos índios, tal como projetado pela política imperial, dependia amplamente de recursos financeiros que viabilizassem a oferta permanente de brindes e que nunca chegaram a ser satisfatórios, dada a extensão do território e a grande quantidade de indígenas a serem atraídos. Os brindes eram necessários não apenas para atraí-los, eis que deveriam continuar sendo ofertados mesmo depois de constituído o aldeamento, visivelmente para manter os índios satisfeitos e dispostos a continuar submetidos ao missionário ou ao diretor parcial.

\section{EM BUSCA DOS AVATARES DO BRANCO ${ }^{6}$}

Esqueceram os presidentes da província de combinar esse resultado previamente com os índios. A notícia de que o governo do Pará doava brindes se espalhou por todos os cantos, e a documentação revela ampla movimentação de índios dirigindo-se à capital para falar diretamente com o presidente. $\mathrm{Na}$ verdade, o Decreto de 24 de julho de 1845 intensificou prática comum mesmo antes de sua publicação. Referindo-se à missão do Tabayo, no Rio Branco, o presidente da província do Pará, Manoel da Silva Paranhos Velozo, em relatório de 15 de agosto de 1844, afirmava: "é constantemente vária e incerta a quantidade dos indígenas que só concorrem à Missão por visita e espírito de curiosidade e atraídos pelo desejo de receber algum presente, o que 
conseguido, retiram-se novamente para os seus alojamentos, ficando o missionário reduzido às pessoas do seu séquito". ${ }^{7}$

Quando os missionários ou diretores parciais não satisfaziam esse "espírito de curiosidade", os índios seguiam longo caminho até o presidente da província. ${ }^{8}$ Assim faziam os Apinayé, por exemplo, muito utilizados na pilotagem das canoas de comércio que navegavam pelos rios Tocantins e Araguaia e que frequentemente estavam em Belém. Do ponto de vista da fronteira dos brancos, os Apinayé pertenciam ao território de Goiás, mas, dizia o presidente Jerônimo Francisco Coelho, “é só o Pará que eles procuram e somente daqui têm eles recebido muitas ferramentas, armas, brindes e fazendas; e se não fora a dificuldade de perder eles os seus estabelecimentos e lavouras já algumas das aldeias se teriam passado para terras do Pará, que ficam fronteiras". ${ }^{9}$ Segundo Marta Amoroso, as populações aldeadas "passam a frequentar os espaços públicos em viagens que buscam a negociação direta com as autoridades das províncias e do Governo do Império, sem os constrangimentos impostos pelos intermediários, sejam eles a Diretoria dos Índios ou os missionários" (Amoroso, 2006, p.121).

Chamo a atenção para a perspectiva Apinayé na escolha do estabelecimento, se não de aliança, pelo menos de contato de caráter relacional e contextual com o governo do Pará, que na leitura indígena poderia lhes proporcionar mais vantagens do que o governo de Goiás. Assim como Elisa Garcia (2008) observou com relação aos Minuanos no Rio Grande do Sul do século XVIII, observa-se a mesma atitude por parte dos Apinayé no sentido de selecionar na trajetória de seus relacionamentos com os não índios os aspectos que lhes eram mais favoráveis, com claro propósito de obter benefícios em momentos específicos.

Os grupos indígenas da Amazônia oitocentista não manejavam a seu favor apenas as diferenças entre os governos provinciais. Diversas pesquisas têm demonstrado como os índios aprenderam a explorar as rivalidades entre as nações fronteiriças, acionando os instrumentos, o vocabulário e a retórica adequados para, numa situação específica, utilizar sua posição na fronteira das nações para auferir benefícios (Farage, 1991; Weber, 2005; Garcia, 2008; Carvalho, 2012). ${ }^{10}$ É o que se depreende do ofício encaminhado por João Paes de Souza, Diretor Geral dos índios, ao presidente da província do Pará, Barão de Santarém, em 16 de novembro de 1872: "inclusa remeto a $V$. Ex $x^{a}$ a relação dos objetos que julgo necessários fornecer aos índios que habitam as cabeceiras do rio Parú, e que vieram pela primeira vez apresentar-se ao Governo com o 
fim, talvez, de continuar a se comunicar conosco, abandonando os Caieneses com quem entretinham negócios". ${ }^{11}$

Na relação de objetos que o diretor apresentou, constam espingardas de fuzil, terçados, facas, miçangas, machados, vários tipos de tecido e, para o “capitão" dos índios, farda, calça, boné e sapatos. Note-se que o Diretor Geral não estava plenamente convicto de que os índios abandonariam os negócios que costumeiramente faziam com a Guiana Francesa (os caieneses), mas mesmo assim solicitou os brindes.

Os índios costumavam receber miçangas, roupas e ferramentas para o trabalho. Em 1854, um grupo de mais de sessenta Tembé desceu das cabeceiras do rio Gurupi, fronteira do Pará com o Maranhão, para um braço do rio Capim, de onde se dirigiram ao presidente da província. Sebastião do Rego Barros mandou batizar as crianças, brindou os índios e os convidou a aproximarem-se, mas ele era bastante consciente de que nada disso significava que os Tembé fossem se fixar em aldeamentos regulares: "essas malocas não formam ainda aldeamentos, nem se pode contar com a sua permanência nestes lugares, para onde têm baixado, pois já por vezes tem acontecido fazerem iguais descidas e desaparecerem pouco depois, internando-se de novo nas brenhas". ${ }^{12}$

Mais de 10 anos depois, os Tembé do rio Capim continuavam surpreendendo as autoridades paraenses. Uma carta anônima publicada no jornal $O$ Liberal do Pará alertava a população da capital do Pará sobre as estratégias indígenas para obter brindes:

A bem do interesse público previne-se a quem competir que os índios do Capim estão todos de muito tempo aldeados e concorrendo para o mercado com os produtos agrícolas de sua lavra, tais como farinha, arroz, tabaco, etc., afora os produtos naturais que extraem. O expendido é porque me consta que uma grande porção de índios vão para a capital, para ser apresentados como coisa nova, a fim de auferir-se coisas, que se recebem a título de brindes, pela verba catequese e que ao depois quem sabe em que elas se empregam. ${ }^{13}$

A verba do governo era destinada para índios considerados selvagens. Depois que fossem considerados civilizados ou confundidos na massa da população local eles não tinham mais direito aos brindes, nem mesmo às terras dos aldeamentos. Conforme Marta Amoroso, "o governo imperial esgotava o compromisso da tutela dos índios quando dava por cumprido o projeto de 
civilização" (Amoroso, 2006, p.137). Note-se, então, a esperteza dos Tembé do rio Capim que, por conta própria ou acompanhados de missionários ou diretores, faziam-se passar por "coisa nova", ou seja, por recentemente aldeados, a fim de obter brindes do governo.

Essa atitude indígena pode ser observada em outras partes do Brasil do mesmo período. Em 1862, o missionário capuchinho frei Pacífico de Montefalco, do Aldeamento de Faxina, em São Paulo, denunciava que "os Kaiowá estavam manipulando o programa de catequese e civilização dos índios, fingindo-se selvagens, quando eram velhos conhecidos da missão católica, ex-catecúmenos casados e batizados nos aldeamentos capuchinhos de São Paulo e Paraná" (Amoroso, 2006, p.138). Na ocasião, os índios "até ficaram pintados", o que demonstrava sua compreensão da maneira como os não índios lidavam com a identidade indígena. Nesse caso, a pintura dos Kaiowá tinha como objetivo fazê-los passar por "coisa nova", tal como faziam os Tembé diante do presidente da província do Pará.

Pesquisas antropológicas têm revelado que muitos grupos indígenas praticam a chamada "reciprocidade protelada", considerando que é importante manter dívidas em aberto, de modo a neutralizar distâncias sociais, temporais e espaciais e forjar complexos sistemas de relações. Isso permite que o ritmo das contraprestações se estenda por anos. Conforme observou Catherine Howard com relação aos índios Waiwai, do oeste do Pará, “[q]uitar a dívida de uma só vez é interpretado como uma manifestação de raiva e um sinal de que se quer 'esquecer' a relação" (Howard, 2002, p.44). Em pesquisa mais recente entre os Deni, no Amazonas, Marcelo Pedro Florido constatou que, para esses índios, "o acesso constante às mercadorias e às potências do mundo não indígena parece ser o que de fato está por trás da relação com os patrões e isto é obtido através da manutenção de uma dívida" (Florido, 2013, p.281).

No discurso dos presidentes da província do Pará, era comum a queixa de que os índios recusavam a permanência nos aldeamentos regulares, onde estariam submetidos à prestação de serviços que, pelo menos em tese, teriam uma contraprestação ou reciprocidade imediata. Do ponto de vista indígena, manter-se internado nas brenhas e aparecer em ocasiões específicas poderia ser uma forma de manter a relação em aberto, tornando-a mais duradoura. ${ }^{14}$ O desencontro se dava porque o "espírito de curiosidade" dos índios, que o Regulamento das Missões procurava estimular, parecia nunca dar-se por satisfeito. Na realidade, se o referido decreto via na doação de brindes uma forma de despertar nos índios o "desejo do trato social", a noção de reciprocidade 
protelada, característica das culturas indígenas, revela formas distintas de se pensar o estabelecimento de alianças ou de "trato social". Tudo indica que, do ponto de vista dos índios, cada detalhe das transações era fixado e regulado por regras e convenções tradicionais nas quais eles procuravam inserir os não índios (Henrique; Morais, 2014).

As autoridades da província ficavam reféns do "espírito de curiosidade" e do desejo dos índios por brindes. O desejo de fixá-los em aldeias e usufruir de sua força de trabalho era mais forte do que a incerteza quanto às suas disposições futuras, razão pela qual os brindes continuavam sendo distribuídos. Além disso, a documentação disponível leva a crer que, nessas ocasiões, os índios costumavam dizer aquilo que os presidentes da província queriam ouvir. Fausto Augusto de Aguiar, depois de brindar os mais de trinta índios Munduruku habitantes de aldeias do rio Tapajós, que o visitaram no palácio do governo, teve a impressão de que eles saíram felizes com o acolhimento que tiveram. Diplomáticos, os Munduruku "ratificaram, nessa ocasião, as manifestações que tinham feito ao missionário, de desejar reunir-se com as suas tribos em aldeias sob sua direção, deixando inteiramente a vida selvagem; e voltaram muito animados pelas promessas, que lhes fiz, de lhes serem dados socorros e proteção". ${ }^{15}$

Boa acolhida no palácio do governo, brindes, promessas de socorros e proteção, eis que os Munduruku tinham razões de sobra para comemorar a visita ao presidente da província. Deixar inteiramente a "vida selvagem", porém, ficou apenas na promessa. Repetiam, assim, a atitude dos Juruna um século antes: tendo recebido ferramentas, tecido e outros objetos, "pouco tempo permaneciam na povoação, retirando-se novamente para a floresta, para retornar em outra ocasião para novos presentes, empenhando-se em novos descimentos" (Sampaio, 2001, p.11). ${ }^{16}$

Muitas vezes o pedido de proteção que os índios faziam ao governo da província tinha como objetivo defendê-los contra inimigos tradicionais, como o fizeram os Pariqui, habitantes das cabeceiras do rio Araguari, que manifestaram intenção de "estabelecerem-se na Cachoeira do rio Vila Nova, a 4 léguas da cidade de Macapá, declarando aqueles índios que, se o governo lhes desse a licença que pediam, eles e toda a sua tribo, que andava acossada por uma outra feroz e antropófaga, fixariam no dito lugar a sua residência". ${ }^{17}$

Vale ressaltar, nesse caso, que a decisão de se fixar em aldeamento regular partiu dos próprios índios, mas a motivação tinha mais a ver com disputas tradicionais indígenas do que com o desejo de se tornar "civilizado". Afinal, 
os Pariqui procuraram o aldeamento por se sentirem acossados por outra etnia inimiga, a qual eles definiram como "feroz e antropófaga", atraindo para seus inimigos tradicionais as atenções bélicas das autoridades da província. Certamente os índios reivindicavam para si a iniciativa do contato e, talvez, da "pacificação dos brancos", ${ }^{18}$ reforçando sua condição de sujeito histórico. De todo modo, não se pode descartar a possibilidade de busca, por parte dos índios, de uma "garantia de intermediação qualificada com o governo que permitisse o abastecimento permanente e um novo patamar de relações políticas" (Carvalho, 2012, p.313). De acordo com Rafael Santos, "muitos dos atos voluntários de aldeamento são explicados por razões que envolveram questões climáticas, doenças, carência por alimentos e até os conflitos com outras nações indígenas" (Santos, 2014, p.112).

Em abril de 1852, duas canoas de Munduruku, de lugares diferentes, apareceram ao frei Egidio de Garésio, que acumulava as funções de missionário e diretor interino do rio Tapajós (Suliman, 2016). Os índios procuravam receber ferramentas, tecidos e ornamentos e argumentavam que tais objetos teriam sido prometidos pelo presidente da província quando eles estiveram em visita à capital. O missionário explicou aos índios que o presidente da província lhes havia prometido ferramentas e brindes com a condição de que cumprissem a promessa feita de se fixar no aldeamento, e alertava-os que agindo "desta maneira estavam enganando o Governo".

Os índios relataram supostas dificuldades para cumprir a promessa, renovada diante da pressão do missionário: "e no fim me prometeram que haviam de descer no mês de julho". Na ocasião, os que estavam completamente nus ganharam calças, e todos receberam terçados, machados, foices, enxadas, pregos, sal e anzóis. Frei Egidio de Garésio registrou, ainda, que os Munduruku haviam dito "que muitos [índios] das campinas se apresentavam a fim de vir receber os mesmos objetos" e que "não é possível ir naqueles lugares sem os mimosear, e um padre levar fazenda a fim de fazer cobrir as partes vergonhosas ao menos às mulheres". ${ }^{19}$

No mesmo ano, o vice-presidente da província do Amazonas, Manoel Gomes Corrêa de Miranda, informava que "grande número de principais têm vindo se apresentar ao Governo e prestar preito e homenagem ante o retrato de S. M. I., e com agrados, e alguns brindes eles têm prometido que vão fazer descer as suas tribos e fundar suas aldeias" ${ }^{20} \mathrm{O}$ fato de que eram os Principais ou tuxauas que se dirigiam ao presidente da província pode ser indicativo da perspicácia indígena em perceber que a voz de suas lideranças teria maior peso 
na hora de negociar brindes em troca da "promessa" de descimento de todos os habitantes das aldeias. Quando isso ocorria, os presidentes da província acreditavam que as promessas dos índios tinham mais chances de ser concretizadas. Note-se, entretanto, que a província do Amazonas acabara de ser estabelecida, o que de certa forma facilitava o acesso de muitos grupos indígenas, que antes precisavam se deslocar até Belém.

Os índios que visitaram o palácio do governo do Pará mostraram-se atualizados sobre as alterações políticas provinciais, além de inserirem no ritual de negociação de brindes uma prática que, aos olhos das autoridades provinciais, era indicativa da vontade de se "civilizar": prestar preito e homenagem ante o retrato do imperador d. Pedro II. Essa atitude demonstra como eles "lançavam mão de recursos performáticos" (Amoroso, 2006, p.138) a fim de conseguir seus objetivos, manipulando a seu favor as diretrizes da política indigenista.

\section{METAMORFOSES, TRADUÇÃo CULTURAL E POLÍTICA INDÍGENA}

\section{Conforme afirmou Catherine Howard,}

os povos indígenas podem até dar a impressão de imitar a cultura dominante ao adotar as roupas dos brancos, querer seus bens, reverenciar seus deuses ou empregar sua retórica para criticá-los, mas a resistência é sempre uma questão híbrida e contraditória, tanto na forma quanto no conteúdo. Na verdade, essa qualidade mimética costuma ser parte de sua eficiência. (Howard, 2002, p.28)

Exemplo bastante significativo dessa "qualidade mimética" foi relatado por Pedro Vicente de Azevedo, presidente da província do Pará, em 1875. Segundo Azevedo, o índio seria como um "papagaio" que "faz automaticamente o que o padre manda" sem compreender o "sentido" da reza que lhe é ensinada. Batizado já em idade adulta, o índio "semicivilizado" pede novamente o batismo a cada ano que passa, escolhendo com antecedência um padrinho. Quando, numa freguesia, ele não consegue mais padrinhos, que se recusam por ele já ter sido batizado, o índio parte para outras freguesias em busca de novos padrinhos, que lhe proporcionarão novos presentes. ${ }^{21}$

Muitas vezes, atitudes como essa eram utilizadas para reforçar o recorrente tema da "inconstância" dos índios, que ao longo da história do Brasil se consolidou como "traço definidor do caráter ameríndio" no imaginário 
nacional (Castro, 1992, p.23; Roller, 2014, p.130). Para alguns, a incompreensão do sentido do sacramento cristão recebido seria justificada por uma espécie de atavismo, daí a inconstância do índio batizado diversas vezes. Para outros, seria reveladora da suposta incapacidade indígena de aprender, sendo ele capaz apenas de imitar (Amoroso, 1998), daí a definição de "índio papagaio", conforme vimos no relato de Pedro Vicente de Azevedo. No século XIX, era recorrente a ideia de que os índios compreendiam mal os elementos do catolicismo por terem sido vítimas da "falsa catequese" ministrada pelos jesuítas (Rayol, 1968; Veríssimo, 1970).

A partir do diálogo mais próximo com a Antropologia, os historiadores têm construído outras leituras dos "recursos performáticos" utilizados pelos índios. Ao analisar a situação dos chamados Botocudos na província de Minas Gerais, no século XIX, Isabel Missagia de Mattos fala em "transitividade lógica da magia”, percebida em situações nas quais, por exemplo, os índios "ao mesmo tempo recusavam o aldeamento missionário e incorporavam símbolos da cristandade como o sinal da cruz" (Mattos, 2004, p.189). A autora também se refere à água benta, que "era considerada pelos botocudos aldeados como instrumento simbólico para a neutralização do 'capeta' escondido na escola indígena" (ibidem, p.409).

Assim, além da possibilidade de receber novos presentes, poderíamos pensar na busca de novos batismos como forma de os índios se apropriarem do simbolismo da água presente no rito, no sentido de instrumento simbólico que purifica e neutraliza o poder dos inimigos. Segundo Paula Montero, "os povos indígenas também praticam a tradução apropriando-se dos modos como os religiosos organizam os sistemas de diferenças no processo mesmo de tradução dos 'costumes”' (2006, p.20). Isso significa que os povos indígenas realizaram a leitura da alteridade dos arautos da civilização nos termos oferecidos por sua própria cultura. É necessário pensar, portanto, o processo de cristianização dos índios junto à indianização do cristianismo.

Nesse sentido, a atitude do "índio papagaio" configuraria o que Cristina Pompa chamou de "surpreendente convergência de horizontes simbólicos", em que se percebe a atualização histórica que os índios fazem do impacto da colonização e da catequese. Trata-se, então, da possibilidade de realizar "a reconstituição da dinâmica pela qual o evento histórico da 'evangelização' foi absorvido e transformado pelas culturas nativas a partir de suas próprias representações" (Pompa, 2006, p.124). 
Alguns relatos de d. José Afonso de Morais Torres servem de exemplo da maneira como os índios fizeram a tradução dos próprios brindes preconizados pela política indigenista na Amazônia do século XIX. Ao fazer um balanço de sua visita pastoral pela província do Pará, em 1846, o bispo relatou que "um tuxaua (principal da nação) disse a um dos diretores de uma aldeia que viria à capital com bastante farinha e guaraná para 'comprar-me um padre' tal era o desejo de possuí-lo" ${ }^{22}$ Curioso perceber como o próprio missionário foi inserido pelo índio no sistema de trocas costumeiramente agenciado por intermédio dos brindes. Dada a percepção do valor que os não índios atribuíam à farinha e ao guaraná, elementos fundamentais nas trocas comerciais da Amazônia oitocentista, nada mais natural do que avaliar que tais produtos haveriam de pagar o preço de um padre!

Como vimos no início deste artigo, as autoridades da província procuravam manter os índios confiantes na aliança com os não índios e dispostos a permanecer nos aldeamentos regulares. Para isso, procuravam ofertar brindes e agradar especialmente os tuxauas, que geralmente recebiam uma farda que os distinguia dos demais. Atitudes semelhantes podem ser vislumbradas entre os índios. Em dezembro de 1840, o Principal dos índios da nação intitulada Coromita compareceu ao comando militar de Portel levando consigo 25 casais indígenas. O tuxaua pediu roupas para si e para sua gente, além de ferramentas, farinha, sal e algumas miudezas. O comandante militar de Portel, major Raimundo Joaquim Pantoja, atendeu a todos esses pedidos e deu ao tuxaua "um fardamento rico". O tuxaua dos Coromita afirmou que estava disposto a reunir seu povo em um aldeamento, mas apresentou algumas condições: "que se lhes permitisse que fizessem o seu aldeamento em um lugar por eles marcado na distância de duas marés dessa freguesia; que lhes não tirassem pessoa alguma de sua maloca durante o espaço de sete anos e que se lhes prestasse todo o auxílio enquanto se não firmasse o seu estabelecimento". ${ }^{23}$

Diante da garantia de que tais condições seriam apresentadas à autoridade maior da província, os índios mostraram-se satisfeitos, relata o presidente da província, "pedindo o Principal que V.S me remetesse quatro flechas e um arco da sua nação com que me brindava”. Em primeiro lugar, note-se o protagonismo indígena ao impor ao presidente da província o local onde deveria ser fundado o aldeamento. Além disso, a "distância de duas marés" da freguesia de Portel indica claramente uma preocupação estratégica, garantia de distância prudente necessária para a manutenção de certa autonomia aos Coromita. 
Entretanto, a exigência de que não se tirasse nenhum índio do aldeamento pelo período de 7 anos revela que os índios tinham conhecimento da finalidade do aldeamento para as autoridades, espaço de oferta de mão de obra barata para as cidades ao redor e para o governo. Dessa forma, os Coromita demonstravam saber que era prática usual a retirada abusiva dos índios dos aldeamentos, que prejudicava a manutenção do convívio familiar entre eles. A propósito, o fato de comparecer no Comando Militar de Portel acompanhado de 25 casais indígenas era indicativo claro da disposição do tuxaua em aderir ao aldeamento, eis que em ocasiões nas quais não queriam estabelecer alianças ou duvidavam de suas condições, mulheres e crianças indígenas dificilmente acompanhavam os índios nas negociações.

Estrategicamente, o presidente da província do Pará, Tristão Pio dos Santos, solicitou ao comandante militar de Portel que dissesse ao Principal dos Coromita que aprovava "a proposta do dito chefe, como as condições com que os mesmos índios se querem estabelecer no lugar por eles escolhido”, além de informar que deveria o comandante militar "agradecer em meu nome ao mencionado chefe dos gentios Coromita o seu presente, que me mandou e recebi” ${ }^{24}$ Cônscio de seu papel, de sua autoridade diante da nação dos Coromita, o Principal procurou não deixar dúvidas quanto a sua intenção de aldear-se com seu povo e, para isso, literalmente brindou o presidente da província com dois objetos de grande valor entre os índios: arco e flecha.

Retirados do contexto da guerra, destituídos simbolicamente de seu poder de destruição do outro ou, quem sabe, neutralizadores do poder de destruição dos não índios, arco e flecha se tornavam sinônimos da aliança que o Principal pretendia estabelecer com a autoridade máxima da província do Pará, a quem ele brindava, de modo a mantê-lo satisfeito e confiante, assim como os presidentes da província tentavam fazer com os índios. ${ }^{25}$

Conforme observou Maria Regina Celestino de Almeida, é necessário pensar as mudanças que atingiram as sociedades indígenas não como simples perdas culturais, mas como propulsoras das novas possibilidades de os índios se adaptarem à realidade imposta pela colonização. Segundo a autora, "no interior dos aldeamentos, os índios misturaram-se e transformaram-se, mas não necessariamente conforme os padrões dos padres e autoridades. Interessavam-se por algumas mudanças e aprendizados, mas tinham nisso seus próprios interesses e atribuíam-lhes rumos e significados próprios" (Almeida, 2013, p.147). Há que se observar, portanto, nos aldeamentos, um duplo processo. De um lado, a metamorfose dos índios, sujeitos ativos desse processo, 
conforme enfatiza a autora: "transformaram-se, portanto, mais do que foram transformados" (2013, p.156). De outro, a metamorfose dos objetos exteriores às culturas tradicionais indígenas, aos quais os índios atribuíam outros significados.

É possível pensar que, para os índios, as ferramentas industrializadas contribuíam para ampliar o ideal de felicidade nativo, a partir do momento em que algumas delas tornavam o trabalho e a colheita mais fácil e abundante (enxadas, terçados e facões, entre outras). Referindo-se aos índios habitantes do rio Gurupi, na fronteira entre Pará e Maranhão, Gustavo Dodt afirmou que "pela introdução de utensílios de ferro e de aço tem-se tornado o trabalho mais suave para os índios" (Dodt, 1981[1873], p.91). Ocorre que esse modelo de felicidade se chocava frontalmente com o que o projeto de catequese e civilização do império propunha para os índios: transformá-los em trabalhadores sedentários e que gerassem excedentes para o comércio.

\section{CONSIDERAÇÕES FINAIS}

Em 1860, 15 anos após a promulgação do Decreto de 24 de julho de 1845, Antonio de Sá e Albuquerque, presidente da província do Pará, se dizia convencido de que o governo estava criando "uma classe de pensionistas, que recebam alimentação, vestuário, e presentes dos cofres públicos, ainda assim esses meios são perdidos; a deserção é certa sem que fique um só traço de utilidade para o país". ${ }^{26}$ Dois anos depois, o presidente da província do Amazonas, Manoel Clementino Carneiro da Cunha, afirmou que "tudo quanto se faz reduz-se a presentes e brindes e os índios continuam na sua vida errante, sem moral e hábitos regulares de trabalho". ${ }^{27}$

Por muito tempo, a presença de objetos manufaturados nas aldeias foi utilizada como parâmetro de avaliação do grau de aculturação, como se a presença de tais objetos denunciasse o quanto esses povos estariam distantes de um modelo ideal de cultura indígena. Pesquisas mais recentes têm demonstrado como, em muitos casos, possuir as ferramentas dos "brancos" constitui para os povos indígenas uma forma de "pacificação dos brancos" (Albert, 2002). Nesse sentido, ter, mas nem sempre manter objetos dos brancos faz parte do processo de domesticação, de esvaziamento de sua agressividade.

Muitos estudos têm demonstrado que parte significativa dos objetos manufaturados recebidos pelos índios não ficam em suas aldeias, sendo 
reinseridos na dinâmica tradicional do comércio interétnico. Ao comentar a presença de objetos nas aldeias Waiwai de fins do século XIX, Catherine Howard observou que "se a quantidade de manufaturados encontrada em cada um dos lugares visitados parecia pequena, era porque eles eram imediatamente passados adiante para grupos mais remotos" (Howard, 2002, p.34).

Entretanto, não devemos imaginar que os objetos manufaturados são absorvidos ou introduzidos nas culturas indígenas com os mesmos significados que eles têm em nossa cultura. Citem-se os trabalhos de Catherine Howard (2002) com relação aos Waiwai e Lúcia Van Velthem (2002) com relação aos Wayana. Mostram as autoras como os objetos podem ser desvinculados de quem os produziu, circulando independentemente destes e sendo submetidos a complexas transformações de significado e valor. Exemplo disso é o relato do major Manoel Ribeiro de Vasconcelos, que em viagem pelo rio Jauaperi, em 1856, na província do Amazonas, encontrou no interior das malocas dos índios Waimiri "peças formadas para diversos usos e construídas com pregos, pedaços de tachos de cobre, de facas, etc., que pela ventura os gentios puderam apanhar nas suas sortidas". ${ }^{28}$ Como vimos ao longo deste artigo, tais metamorfoses dos objetos, ocorrendo de forma sutil, mas eficaz, é considerada tão política em sua natureza quanto as formas mais explícitas de protesto.

Howard cita o relato de Schomburgk ${ }^{29}$ sobre um índio Barokoto do rio Essequibo, na fronteira norte do Brasil, que foi instado a abrir as sepulturas onde estavam enterradas suas duas mulheres, a sogra e uma criança. Entre os despojos encontrados junto ao corpo de sua esposa mais velha haviam sido depositadas uma garrafa e uma caneca. O índio afirmou que a própria mulher havia lhe pedido isso, para não sentir sede a caminho do outro mundo. No túmulo da mais nova havia algumas miçangas de vidro e peças de vestuário. Junto aos restos da criança havia um espelho e um terçado quebrado, e junto ao túmulo da mulher mais velha havia algumas miçangas de vidro (Howard, 2002, p.32). Nesse caso, note-se que os objetos dos brancos foram incorporados à cosmologia indígena, mas a partir de significados bastante distintos daqueles que possuíam em sua cultura originária. Os objetos são "processados" pela trama social, sua inserção nas culturas indígenas é mediada pelos valores desta, num esforço constante de imprimir nesses objetos sua marca distintiva.

O estudo da relação dos índios com os objetos das culturas não indígenas permite rever a ideia de que os índios eram ingênuos e sempre vítimas dos colonizadores. Tantas vezes definidos como bugigangas, quinquilharias, objetos sem nenhum valor, os "brindes" dados aos índios exigem do historiador 
leitura que vá além de seu valor meramente comercial. ${ }^{30}$ Há toda uma dimensão simbólica envolvida na apropriação que os índios faziam de tais "brindes", além da evidente capacidade indígena de articular uma prática e um discurso capazes de garantir junto à maior autoridade da província, do Império ou da Igreja a satisfação de seu desejo por mercadorias. Afinal, eles sabiam exatamente a quem se dirigir, onde seria mais fácil conseguir mercadorias e qual discurso deveriam utilizar para esse fim.

\section{REFERENNCIAS}

ALBERT, Bruce. Introdução, Cosmologias do contato no Norte-Amazônico. In: ALBERT, Bruce; RAMOS, Alcida Rita. Pacificando o branco: cosmologias do contato no norte-amazônico. São Paulo: Ed. Unesp; Imprensa oficial do Estado, 2002. p.9-21.

ALMEIDA, Maria Regina Celestino de. Metamorfoses indígenas: identidade e cultura nas aldeias coloniais do Rio de Janeiro. 2.ed. Rio de Janeiro: Ed. FGV, 2013.

AMOROSO, Marta. Crânios e cachaça: coleções ameríndias e exposições no século XIX. Revista de História, São Paulo, n.154, p.119-150, 2006.

Mudança de hábito: Catequese e educação para índios nos aldeamentos capuchinhos. Revista Brasileira de Ciências Sociais, São Paulo, v.13, n.37, p.101-114, jun. 1998.

APOLINÁRIO, Juciene Ricarte. Os Akroá e outros povos indígenas nas fronteiras do sertão: as práticas das políticas indígena e indigenista no norte da capitania de Goiás, século XVIII. Dissertação (Mestrado) - Programa de Pós-Graduação em História, Universidade Federal de Pernambuco (UFPE). Recife, 2005.

BARR, Juliana. Peace came in the form of a woman: Indians and Spaniards in the Texas borderlands. Chapel Hill: The University of North Carolina Press, 2007.

BARR, Juliana; COUNTRYMAN, Edward (Ed.) Contested Spaces on Early America. Philadelphia: University of Pennsylvania Press, 2014.

BAUDRILLARD, Jean. Pour une critique de l'économie politique du signe. Paris: Gallimard, 1972.

CARVALHO, Francismar Alex Lopes de. Lealdades negociadas: povos indígenas e a expansão dos impérios ibéricos nas regiões centrais da América do Sul (segunda metade do século XVIII). Tese (Doutorado) - Programa de Pós-graduação em História Econômica, Universidade de São Paulo (USP). São Paulo, 2012.

CASTRO, Eduardo Viveiros de. O mármore e a murta: sobre a inconstância da alma selvagem. Revista de Antropologia (USP), São Paulo, v.35, p.21-74, 1992. 
DODT, Gustavo. Descrição dos rios Parnaíba e Gurupi. (1873). Belo Horizonte: Itatiaia, 1981.

FARAGE, Nádia. As muralhas dos sertões: os povos indígenas no rio Branco e a colonização. Rio de Janeiro: Paz e Terra; Anpocs, 1991.

FLORIDO, Marcelo Pedro. O manakuni dos Deni: prestações e contraprestações no rio Cuniuá (AM). In: AMOROSO, Marta; SANTOS, Gilton Mendes dos. Paisagens ameríndias: lugares, circuitos e modos de vida na Amazônia. São Paulo: Terceiro Nome, 2013. p.275-298.

FONTENELE, Francisca Nescylene. Grão-Pará pombalina: trabalho, desigualdade e relações de poder. Dissertação (Mestrado) - Programa de Estudos Pós-Graduados em História, Pontifícia Universidade Católica de São Paulo (PUC-SP). São Paulo, 2008.

GARCIA, Elisa Frühauf. Quando os índios escolhem seus aliados: as relações de 'amizade' entre os minuanos e os lusitanos no sul da América portuguesa (c.1750-1800). Varia Historia, Belo Horizonte, v.24, n.40, p.613-632, jul./dez. 2008.

HARRIS, Mark. Rebelion on the Amazon: the Cabanagem, Race and Popular Culture in the North of Brazil, 1798-1840. New York: Cambridge University Press, 2010.

HEMMING, John. Fronteira amazônica: a derrota dos índios brasileiros. São Paulo: Edusp, 2009.

HENRIQUE, Márcio Couto. A perspectiva indígena das missões religiosas na Amazônia (século XIX). Revista História Social, São Paulo, v.I, p.133-156, 2013.

HENRIQUE, Márcio Couto; MORAIS, Laura Trindade. Estradas líquidas, comércio sólido: índios e regatões na Amazônia (século XIX). Revista de História (USP), São Paulo, v.171, p.49-82, 2014.

HOWARD, Catherine V. A domesticação das mercadorias: estratégias Waiwai. In: ALBERT, Bruce; RAMOS, Alcida Rita. Pacificando o branco: cosmologias do contato no norte-amazônico. São Paulo: Ed. Unesp; Imprensa Oficial do Estado, 2002. p.25-55.

MALINOWSKI, Bronislaw. Argonautas do Pacífico Ocidental. São Paulo: Ed. Abril, 1978. (Coleção “Os Pensadores").

MANDRINI, Raúl José. Transformations: The Rio de la Plata during the Bourbon Era. In: BARR, Juliana; COUNTRYMAN, Edward (Ed.) Contested Spaces on Early America. Philadelphia: University of Pennsylvania Press, 2014. p.143-160.

MATTOS, Isabel Missagia de. Civilização e revolta: os Botocudos e a catequese na Província de Minas. Bauru, SP: Edusc, 2004.

MELO, Vinícius Zúniga. Os Diretores de Povoações: serviços e transgressões no Grão-Pará do Diretório dos Índios (1757-1798). Dissertação (Mestrado) - Programa de Pós-Graduação em História, Universidade Federal do Pará (UFPA). Belém, 2016. MONTEIRO, John Manuel. Negros da terra: índios e bandeirantes nas origens de São Paulo. São Paulo: Companhia das Letras, 1995. 
MONTERO, Paula (Org.) Deus na aldeia: missionários, índios e mediação cultural. São Paulo: Globo, 2006.

PARAÍSO, Maria Hilda Baqueiro. O tempo da dor e do trabalho: a conquista dos territórios indígenas nos Sertões do Leste. Tese (Doutorado) - Programa de PósGraduação em História Social, Universidade de São Paulo (USP). São Paulo, 1998. POMPA, Cristina. Para uma antropologia histórica das missões. In: MONTERO, Paula (Org.) Deus na aldeia: missionários, índios e mediação cultural. São Paulo: Globo, 2006.

RAYOL, Domingos Antonio. Catequese de índios no Pará. Annaes da Bibliotheca e Archivo Público do Pará, Belém, Tomo II, p.117-183, 1968.

RIBEIRO, Darcy. Os índios e a civilização: a integração das populações indígenas no Brasil moderno. Petrópolis, RJ: Vozes, 1979.

RICCI, Magda. Cabanagem, cidadania e identidade revolucionária: o problema do patriotismo na Amazônia entre 1835 e 1840. Tempo, v.11, p.15-40, 2006.

ROLLER, Heather F. Amazonian Routes: Indigenous Mobility and Colonial Communities in Northern Brazil. Palo Alto, CA: Stanford University Press, 2014.

SAHLINS, Marshal. Cultura e razão prática. Rio de Janeiro: Jorge Zahar, 2003.

SAMPAIO, Patrícia Melo. Espelhos partidos: etnia, legislação e desigualdade na Colônia, Sertões do Grão-Pará, c.1755-c.1823. Tese (Doutorado) - Programa de Pós-Graduação em História, Universidade Federal Fluminense (UFF). Niterói, 2001. . Política indigenista no Brasil imperial. In: GRINBERG, Keila; SALLES, Ricardo. O Brasil imperial. v.I: 1808-1831. Rio de Janeiro: Civilização Brasileira, 2009. p.175-206.

SAMPAIO, Patrícia Melo; ERTHAL, Regina de Carvalho. Rastros da memória: histórias e trajetórias das populações indígenas na Amazônia. Manaus: Edua, 2006.

SANTOS, Rafael Rogério Nascimento dos. “Dis o índio...”: outra dimensão da lei políticas indígenas no âmbito do Diretório dos Índios (1777-1798). Dissertação (Mestrado) - Programa de Pós-Graduação em História, Universidade Federal do Pará (UFPA). Belém, 2014.

SCHOMBURGK, Robert Herman. A Description of British Guiana, Geographical and Statistical: Exhibiting its Resources and Capabilities, Together with the Present and Future Condition and Prospects of the Colony. London: Simpkin, Marshall \& Co., 1840.

SOMMER, Bárbara. Negotiated settlements: native Amazonians and Portuguese policy in Pará, Brazil, 1758-1798. PhD Thesis - University of New Mexico. Albuquerque, NM, 2000.

SPOSITO, Fernanda. Nem cidadãos, nem brasileiros: indígenas na formação do Estado nacional brasileiro e conflitos na província de São Paulo (1822-1845). Dissertação (Mestrado) - Programa de Pós-Graduação em História Social, Universidade de São Paulo (USP). São Paulo, 2006. 
SULIMAN, Sara da Silva. O capuchinho e os Munduruku: um estudo sobre a missão do Baixo Tapajós (Pará, 1848-1855). Dissertação (Mestrado) - Programa de Pós-Graduação em História, Universidade Federal do Pará (UFPA). Belém, 2016.

VELTHEM, Lúcia Hussak van. Feito por inimigos. Os brancos e seus bens nas representações Wayana do contato. In: ALBERT, Bruce; RAMOS, Alcida Rita. Pacificando o branco: cosmologias do contato no norte-amazônico. São Paulo: Ed. Unesp; Imprensa oficial do Estado, 2002. p.61-83.

VERÍSSIMO, José. Estudos Amazônicos. Belém: Ed. UFPA, 1970.

WEBER, David J. Bárbaros: Spaniards and Their Savages in the Age of Enlightenment. New Haven and London: Yale University Press, 2005.

\section{NOTAS}

${ }^{1}$ Pós-Doutor em História pela Universitat de Barcelona, professor da Faculdade de História e do Programa de Pós-Graduação em História da Universidade Federal do Pará (UFPA). Coautor do dossiê Círio de Nazaré (Iphan, 2006) e autor de Um toque de voyeurismo: o diário íntimo de Couto de Magalhães (1880-1887), Rio de Janeiro: Eduerj, 2009.

${ }^{2}$ Versão inicial deste texto foi apresentada no Simpósio Temático “A presença indígena na história do Brasil”, durante reunião da Anpuh em Natal, Rio Grande do Norte, em 2013. A versão atual é um desdobramento do projeto de pesquisa "Os espartanos da Amazônia: história dos Munduruku (1801-1896)", desenvolvido junto à Propesp/UFPA. Agradeço a Anna Linhares e Rafael Chambouleyron os comentários e sugestões.

${ }^{3}$ Apesar de não ser previsto no Decreto de 24 de julho de 1845, que regulamentava a atividade missionária no Brasil imperial, o fornecimento de farda aos tuxauas, ou "Principais", era comum na Amazônia do século XIX. Sua motivação estava associada a fatores tais como a distinção simbólica das lideranças indígenas, recompensas por serviços prestados ao projeto de catequese e civilização dos índios, e a ideia de ordem social associada ao fardamento. A estratégia de distinguir e presentear os Principais das aldeias, no entanto, constituía prática antiga no Brasil, como forma de incrementar o poder de lideranças favoráveis e, desse modo, interferir nas dinâmicas das políticas indígenas. Com relação à Amazônia colonial, SOMMER (2000) considera a formação e consolidação das "hierarquias indígenas" como um desdobramento do Diretório pombalino. Com base nessa ideia, SAMPAIO (2001) afirma que tais "hierarquias indígenas" teriam se configurado a partir das ações de catequese e das próprias estratégias de sobrevivência dos índios. Reconhecida pelo aparato legal, essa elite indígena estabelecia relações de mediação com os agentes do mundo colonial, ingerindo em diferentes espaços de poder (FONTENELE, 2008). Mas, em muitos casos, líderes favoráveis em um momento poderiam se transformar em inimigos dos conquistadores, conforme a situação. Autoras como SAMPAIO (2001), APOLINÁRIO (2005) e MELO (2016) indicam vários casos nesse sentido. Sobre a oferta de "signos distintivos" aos índios na América espanhola, conferir CARVALHO, 2012. 
${ }^{4}$ Voz de Nazaré, Belém, 23 jul. 1978, p.3.

${ }^{5}$ PARÁ, Governo. Falla dirigida pelo exm.o snr. conselheiro Jeronimo Francisco Coelho, presidente da província do Gram-Pará, à Assembléa Legislativa Provincial na abertura da sessão ordinária da sexta legislatura no dia $1^{\circ}$ de outubro de 1848. Pará, Typ. de Santos \& Filhos, 1848, p.102.

${ }^{6}$ A expressão "avatar" inspira-se em FARAGE (1991, p.76), que assim se referiu aos objetos holandeses que circulavam entre os índios na Amazônia do século XVIII.

${ }^{7}$ PARÁ, Governo. Discurso recitado pelo exm.o snr. desembargador Manoel Paranhos da Silva Vellozo, presidente da província do Pará, na abertura da $1^{a}$ sessão da $4^{a}$ legislatura da Assembléa Provincial no dia 15 de agosto de 1844. Pará, Typ. de Santos \& Menores, 1844, p.16.

${ }^{8}$ Muitos índios se dirigiam diretamente ao Imperador. Citando a obra Viagem pitoresca de Debret, John Hemming afirmou que, tão logo proclamada a independência do Brasil, viam-se no Rio de Janeiro "frequentes deputações de índios selvagens que vinham solicitar, do soberano, instrumentos de trabalho, na qualidade de cultivadores, ou armas, para servirem nos corpos auxiliares" (Debret apud HEMMING, 2009, p.196). Para Hemming, "ferramentas de metal eram e ainda são o meio mais eficiente de ganhar a amizade de tribos hostis ou ainda não contatadas" (2009, p.196). Em todo caso, o autor reconhece que "os índios tinham inteligência bastante para adquirir as ferramentas de que necessitavam sem ter de trabalhar para obter mais" (2009, p.197).

9 PARÁ, Governo. Falla dirigida pelo exm.o sñr conselheiro Jeronimo Francisco Coelho, prezidente da província do Gram Pará á Assembléa Legislativa Provincial na abertura da segunda sessão ordinaria da sexta legislatura no dia $1^{\circ}$ de outubro de 1849. Pará, Typ. de Santos \& Filhos, 1849, p.84.

${ }^{10}$ Inspirada nas ideias de David Weber, a coletânea Contested Spaces of Early America (BARR; COUNTRYMAN, 2014) reúne uma série de artigos em que a noção de fronteira é tratada não como um limite, mas como um espaço social, como área de contato entre diferentes sociedades. Nessa perspectiva, compreende-se que as relações ocorridas entre colonizadores e índios nesse espaço foram mais complexas, envolvendo todos os níveis da vida social e indo além de situações de competição, conflito e violência. Em outro interessante livro, BARR (2007) analisa como os índios determinaram os termos de contato, diplomacia, aliança e hostilidade em suas relações com os espanhóis na fronteira do Texas, no século XVIII.

${ }^{11}$ ARQUIVO PÚBLICO DO ESTADO DO PARÁ, Secretaria da Presidência da Província. Série: Ofícios de autoridades eclesiásticas. Caixa 328, 16 nov. 1872.

${ }^{12}$ PARÁ, Governo. Falla que o exm. snr. conselheiro Sebastião do Rego Barros, prezidente desta província, dirigiu á Assembléa Legislativa provincial na abertura da mesma Assembléa no dia 15 de agosto de 1854. Pará, Typ. da Aurora Paraense, 1854, p.37.

${ }^{13}$ O Liberal do Pará, Belém, 30 mar. 1870, p.1.

${ }^{14}$ Malinowski, considerado um dos fundadores da pesquisa de campo antropológica, observou que entre os habitantes de Trobriand "a parceria entre dois indivíduos no kula é 
para sempre" (1978, p.76). Ele também observou que "o kula não se realiza sob a pressão de quaisquer necessidades, visto que seu objetivo principal é o de permuta de artigos que não têm nenhuma utilidade prática" (1978, p.77). Todo o movimento das trocas girava em torno da noção de reciprocidade protelada, pois para os nativos do Kula, "possuir é dar" e nesse aspecto, Malinowski observa que "eles são notavelmente diferentes de nós" (1978, p.85). Talvez a atitude dos índios de sempre exigir brindes diante das autoridades da província do Pará também possa ser entendida a partir da noção de que "possuir é dar". A atitude de possuir, mas não dar, gerava situações como a de um índio Gamela, em Goiás, que ameaçou de morte o missionário que se recusou a dar-lhe um machado (APOLINÁRIO, 2005, p.60).

${ }^{15}$ PARÁ, Relatório do Presidente da Província do Gram-Pará, o Exm. Sr. Fausto Augusto de Aguiar, na abertura da segunda sessão ordinária da sétima legislatura da assembléa provincial, no dia 15 de agosto de 1851. Pará, Typographia de Santos \& Filhos, 1851, p.56-57.

${ }^{16}$ Em Amazonian Routes, ROLLER (2014) argumenta que a mobilidade espacial constitui a chave para a compreensão desse tipo de atitude dos índios, que assim usufruíam certo grau de autonomia com relação aos núcleos coloniais. O sistema colonial português dependia das formas nativas de mobilidade espacial, tendo que criar estratégias de atração dos índios para o desempenho de funções fundamentais como a pilotagem das canoas ou a extração das chamadas drogas do sertão. Esse modo nativo de uso do espaço, analisado por Roller no período do Diretório pombalino, se estendeu além dos séculos XVIII-XIX. Antes desse autor, HARRIS (2010, p.52) havia observado que essa "mobilidade desorganizada" constituía um entrave aos interesses das autoridades locais e nacionais, desejosas de uma população disposta a trabalhar a terra de modo regular.

${ }^{17}$ PARÁ, Governo. Falla dirigida à Assembléa Legislativa da província do Pará na segunda sessão da XI legislatura pelo exm. sr. tenente coronel Manoel de Frias e Vasconcellos, presidente da mesma província, em 1 de outubro de 1859. Pará, Typ. Commercial de A.J.R. Guimarães, [n.d.], p.60, grifos meus.

${ }^{18}$ RIBEIRO (1979) relatou que, para muitas etnias indígenas, elas é que estavam "amansando" os brancos no processo de pacificação. Ao analisar a experiência colonizadora na região dos pampas argentinos, Raúl José Mandrini observou que uma das estratégias utilizadas para enfrentar a resistência indígena foi a oferta de presentes e a aproximação com os caciques. Entretanto, em várias ocasiões foram os próprios caciques que procuraram o contato pacífico com as autoridades espanholas, pois desse modo eles conseguiriam obter presentes, ajuda econômica e militar a ser utilizada na resolução de seus conflitos internos (MANDRINI, 2014, p.151). O autor destaca o papel desses caciques no processo de pacificação que, antes, era atribuído pela historiografia tradicional argentina exclusivamente às autoridades espanholas.

${ }^{19}$ ARQUIVO PÚBLICO DO ESTADO DO PARÁ, Secretaria da Presidência da Província. Série: Ofícios de autoridades eclesiásticas. Caixa 154, 5 abr. 1852.

${ }^{20}$ AMAZONAS, Governo. Falla dirigida à Assembléa Legislativa da província do Amazonas, na abertura da $1^{\text {a }}$ sessão ordinária da primeira legislatura, pelo Exm.o vice-prezidente 
da mesma província, o dr. Manoel Gomes Correa de Miranda, em 5 de setembro de 1852. Capital do Amazonas, Typ. de M. da S. Ramos, 1852, p.13.

${ }^{21}$ PARÁ, Governo. Relatório apresentado ao exm. senr. dr. Francisco Maria Corrêa de Sá e Benevides pelo exm. senr. dr. Pedro Vicente de Azevedo, por occasião de passar-lhe a administração da província do Pará, no dia 17 de janeiro de 1875. Pará, [Typ. de F.C. Rhossard], 1875, p.56.

${ }^{22}$ Voz de Nazaré, Belém, 21 maio 1978, p.3.

${ }^{23}$ Treze de Maio, Belém, 23 dez. 1840, p.324.

${ }^{24}$ Ibidem.

${ }^{25}$ Situação semelhante ocorreu por ocasião do acordo de paz entre os Akroá e as autoridades portuguesas no norte de Goiás: para demonstrar sua disposição pacífica, o Principal dos Akroá enviou aos conquistadores raízes de plantas tradicionalmente utilizadas como alimentos, cura de doenças e rituais, além de algumas frutas silvestres, recebendo em troca, entre outros objetos, machados e facas (APOLINÁRIO, 2005, p.51).

${ }^{26}$ PARÁ, Governo. Relatório que o ex.mo sr. dr. Antonio Coelho de Sá e Albuquerque, presidente da província do Pará, apresentou ao exm.o sr.vice-presidente, dr. Fabio Alexandrino de Carvalho Reis, ao passar-lhe a administração da mesma província em 12 de maio de 1860. Pará, Typ. Commercial de A.J. Rabello Guimarães, 1860, p.31.

${ }^{27}$ AMAZONAS, Governo. Relatório apresentado à Assembléa Legislativa da província do Amazonas pelo exm.o senr. dr. Manoel Clementino Carneiro da Cunha, presidente da mesma província, na sessão ordinária de 3 de maio de 1862. Pará, Typ. de Frederico Carlos Rhossard, 1862, p.15.

${ }^{28}$ AMAZONAS, Governo. Relatório apresentado à Assembléa Legislativa Rovincial [sic], pelo excellentissimo senhor doutor João Pedro Dias Vieira, digníssimo presidente desta província, no dia 8 de julho de 1856 por occasião da primeira sessão ordinária da terceira legislatura da mesma Assembléa. Barra do Rio Negro, Typ. de F.J.S. Ramos, 1856, anexo 6, p.2.

${ }^{29}$ Explorador britânico que fez várias incursões à Guiana inglesa, mapeando e fixando as fronteiras inglesas com a Venezuela, Suriname e Brasil. Conferir SCHOMBURGK, 1840.

${ }^{30}$ Em sua análise sobre as relações entre índios e bandeirantes em São Paulo colonial, Monteiro observou que "tanto a aquisição quanto a oferta de 'mercadorias' devem ser compreendidas mais em termos de sua carga simbólica do que por seu significado comercial” (MONTEIRO, 1995, p.32). Sobre o significado social dos objetos, conferir BAUDRILLARD, 1972; SAHLINS, 2003. Para uma análise das relações entre índios e regatões na Amazônia do século XIX, nessa perspectiva, conferir HENRIQUE; MORAIS, 2014.

Artigo recebido em 18 de maio de 2016. Aprovado em 18 de novembro de 2016. 